\title{
DO CONSUMO À PRODUÇÃO DE LIXO
}

\section{FROM CONSUMPTION TO WASTE PRODUCTION}

\author{
Eduardo de Faria Nogueira \\ Universidade Norte do Paraná - PR \\ eduardo_f_nogueira@hotmail.com \\ Sonia Regina Vargas Mansano \\ Universidade Norte do Paraná - PR \\ mansano@uel.br
}

Submissão: $17 / 05 / 2019$

Aprovação: 13/08/2021

\begin{abstract}
RESUMO
A produção e destinação correta de lixo despontam como um dos maiores problemas emergentes no espaço urbano. Este artigo busca problematizar a indissociabilidade entre consumo e produção de lixo, analisando seus efeitos corrosivos. Para tanto, primeiro é realizada a problematização teórica sobre três pontos: a ascensão histórica do consumo após a Segunda Guerra Mundial; a produção de uma subjetividade consumidora que naturaliza as práticas de consumo sem preocupação com seu resultado; e, por fim, as crises ambientais e os desafios da destinação de resíduos sólidos. Na parte empírica, é apresentado o estudo de caso realizado em uma Organização Não Governamental (ONG) que se ocupa do recolhimento, tratamento e destinação do lixo eletrônico. Como resultado parcial, constata-se que a dissociação entre consumo e produção de lixo consolida-se como um grande desafio urbano, demandando debate amplo a fim de implicar a esfera pública, a gestão das organizações e a população no combate aos efeitos ambientais decorrentes dessa prática.
\end{abstract}

Palavras-chave: Sustentabilidade; Consumo; Lixo.

\begin{abstract}
The production and correct disposal of waste emerge as one of the biggest problems in urban space. The present article addresses the inseparability of consumption and waste production, analyzing the corrosive effects. We first present a theoretical overview of three topics: the historical rise of consumption after World War II, the production of a consumer subjectivity that naturalizes consumption without any kind of concern with the consequences, and, finally, the environmental crises and the challenges of solid waste. The case study presents a NonGovernmental Organization (NGO) that works with the collection, treatment, and disposal of electronic waste. As a partial result, we noted that the dissociation of consumption and waste production is one of the great challenges for cities, demanding a broad debate in order to involve the public sphere, organizations and the population in the fight against the effects of this practice.
\end{abstract}

Key words: Sustainability; Consumption; Waste. 


\section{$1 \quad$ INTRODUÇÃO}

Uma das principais características da sociedade contemporânea é o consumo que engloba os mais variados objetos e serviços oferecidos a um público interessado em conhecer as comodidades, benefícios e prazeres a eles vinculados. A fim de compreender essa característica social, Baudrillard (1995) propôs o termo "sociedade de consumo". O que chama a atenção nessa denominação é a dimensão subjetiva transformada em uma oportunidade de mercado. Assim, valores e imagens que apelam para questões subjetivas passam a ser vinculados às mercadorias e serviços, tornando-se uma força propulsora da sociedade capitalista e sendo disseminados como algo vital.

No entanto, a promoção de um estilo de vida pautado no consumo tem causado sérios danos ambientais e sociais com consequências muitas vezes irreversíveis (O'CONNOR, 2002; FOLADORI, 2001; SASSEN, 2016; FORTI, 2019). O aspecto consumista da sociedade contemporânea, em larga medida, negligenciou a capacidade de suporte do meio ambiente diante da produção inevitável de lixo e da exploração sistemática de recursos naturais.

Tomando em análise esse cenário, o presente artigo tem por objetivo compreender os efeitos socioambientais causados pelo consumo e por sua consequente produção de lixo a partir do estudo de caso de uma Organização Não Governamental (ONG) que atua no ramo de reciclagem de lixo eletrônico. Para tanto, o trabalho foi dividido em duas partes: teórica e empírica. Na parte teórica, são apresentadas três dimensões: primeiramente, é descrito um cenário geral sobre a disseminação e intensificação do consumo após a Segunda Guerra Mundial. Em seguida, busca-se analisar como a noção de subjetividade é operacionalizada para consolidar uma sociedade consumidora. Por fim, é apresentado um panorama de crise ambiental global que tem no consumo e na produção de lixo seu maior descompasso. Na parte empírica, apresenta-se o estudo de caso sobre a referida ONG, que se dedica ao recolhimento, tratamento e destinação de resíduos sólidos em uma cidade localizada no interior do estado do Paraná.

Ao fazer uma articulação entre produção de mercadorias, consumo e produção de lixo, o presente estudo justifica-se por apontar a insustentabilidade advinda do consumismo que caracteriza as sociedades contemporâneas, o que evidencia a necessidade de uma gestão urgente sobre a correta destinação de lixo. Ao final dessa trajetória teórica e empírica, será possível evidenciar, como conclusão parcial, o grande desafio que está colocado para o século XXI: reconhecer e enfrentar a ligação indissociável entre produção, consumo e lixo.

\section{FUNDAMENTAÇÃO TEÓRICA}

\subsection{O consumo na sociedade capitalista pós-guerra}

O consumo de bens e serviços tornou-se prática central da sociedade contemporânea. Ele tornou-se uma prática comum, naturalizada e, às vezes, até banal. Passamos a vida consumindo diariamente, muitas vezes sem planejamento, apesar da necessidade de um aporte financeiro para sustentar esse consumo, que se tornou um hábito socialmente compartilhado. Toda sociedade, seja ela antiga ou moderna, utiliza-se do universo material que está à sua volta para suprir necessidades físicas e sociais. Mais recentemente, para além do âmbito material, o consumo passou a ser compreendido também como suporte para as relações sociais. $\mathrm{O}$ ato de consumir ganhou status, ou seja, tornou-se distintivo de uma condição social, estabelecendo vínculos entre pessoas e grupos. Para Lima (2010, p. 8-9) "a troca e o uso de objetos são práticas que criam e mantém vínculos entre os membros de uma sociedade e que, ao mesmo tempo, operam para fornecer sentido e ordenar a vida coletiva em uma totalidade". Nesse sentido, desde as últimas décadas do século passado, a questão do consumo 
tem atraído a atenção de estudiosos e teóricos sociais (BARBOSA, 2004; KRENAK, 2020b), tornando-se um tema relevante nos debates atuais.

Desde as primeiras décadas do século XX, em função dos avanços industriais, a produção de bens e as práticas de consumo cresceram de maneira exponencial. O mundo ficou tão vinculado ao processo de produzir, vender e consumir mercadorias e/ou serviços que não conseguimos imaginar qualquer outra forma de estruturação dos negócios. Rifkin diz:

\begin{abstract}
Somos ensinados que adquirir e acumular bens materiais faz parte integral de nossa estada na Terra e que somos, pelo menos em parte, um reflexo do que temos. Nossa própria noção do modo como o mundo funciona baseia-se, em grande extensão, no que passamos a considerar como a necessidade primordial de trocar bens uns com os outros e de nos tornarmos membros da sociedade que possuem posses (RIFKIN, 2001, p. 3).
\end{abstract}

De fato, a economia capitalista contemporânea é baseada fundamentalmente nas premissas da produção e do consumo, sendo que esses dois termos são irredutíveis e indissociáveis. Sobre isso, Krenak (2020a, p. 45) alerta: "A experiência das pessoas em diferentes lugares do mundo se projeta na mercadoria, significando que ela é tudo o que está fora de nós”. Isso gera práticas de exploração que levam à “exaustão das florestas, dos rios, das montanhas, nos colocando num dilema em que parece que a única possibilidade para que comunidades humanas continuem a existir é à custa da exaustão de todas as outras partes da vida" (KRENAK, 2020a, p. 46).

Nesse contexto predatório, a industrialização e o comércio tiveram papel de destaque e o aumento da produção tornou-se indispensável para manter essa configuração socioeconômica. Em função do desenvolvimento industrial, já mencionado, acrescido de novas estratégias de produção em massa edificadas pelos métodos taylorista e fordista, emerge a necessidade de criar novos mercados e buscar novas maneiras de estimular a população a aderir ao consumo. Sobre isso, Rifkin (2001, p. 84) assinala: "Frederic Taylor introduziu seus princípios de administração científica nas oficinas e nos escritórios das fábricas, revolucionando a organização de produção".

O fordismo, como método racional de industrialização, também foi fundamental nessa época como "engenharia social orientada pela ordem" (BAUMAN, 2001, p. 68), repercutindo no âmbito do consumo. Tamanha foi a repercussão dos métodos de Taylor e, posteriormente, de Ford, que ambos se tornaram referências para o avanço das indústrias. Bauman esclarece que como o "capitalismo pesado" (2001, p. 69), centrado na produção de bens materiais, estava em ampla ascensão, o taylorismo e o fordismo passaram a ser os principais modos de organização produtiva da sociedade moderna, interferindo em toda a cadeia industrial e ampliando a produção em um volume significativo. Isso repercutiu diretamente nas novas diretrizes para o consumo: os estoques precisavam ser liquidados, ou seja, consumidos.

No entanto, apenas o aumento da produtividade não era o bastante para que o sistema pudesse se manter e avançar. Foi quando o consumidor ganhou papel relevante para sofisticar o funcionamento desse sistema. Isso evidenciava a importância de as pessoas adquirirem produtos e, dessa forma, contribuírem para a continuidade da cadeia produtiva das indústrias. A partir do período pós-Segunda Guerra, ganham espaço as áreas de marketing e comunicação na disseminação e consolidação do consumo (COBRA, 2002; SANTOS et al, 2009). O marketing, em larga escala, se intensificou após os anos 1950, especialmente graças aos meios de comunicação em massa. As tecnologias de informação e comunicação de massa também colaboraram para estreitar a relação entre empresas e clientes, impactando fortemente o mercado. Rifkin mostra que, em meados de 1960,

A maioria das famílias tinha dois automóveis na garagem, lavadoras e secadoras nas lavanderias, aparelho de TV em cores ligado, no último volume, praticamente na 
sala de todas as casas. As empresas começaram a enfrentar uma nova realidade: a superprodução versus a queda na demanda de consumo. A questão não era mais como produzir com rapidez suficiente para acompanhar o mercado de consumo, mas como captar e manter atenção do consumidor por tempo suficiente para torná-lo um cliente fiel, ao longo do tempo (RIFKIN, 2001, p. 86-87).

O marketing e a comunicação tornaram-se instrumentos fundamentais para a configuração de uma nova estratégia de estímulo ao consumo. Suas intervenções buscavam atender às novas necessidades individuais e coletivas, apresentando o consumo como fonte de suprimento das satisfações pessoais. Além disso, foi evidenciada a tendência das fábricas em disseminar a prática sistemática da chamada obsolescência programada (SILVA, 2012; LAYRARGUES, 2011). Atrelada à intervenção do marketing e da comunicação em massa, as indústrias e os governos, sobretudo o norte-americano, passaram a utilizar a obsolescência programada como uma das principais estratégias de estímulo para que os consumidores pudessem aderir às novidades colocadas no mercado, cuja durabilidade era bastante reduzida. A obsolescência programada corresponde a um procedimento intencional que objetiva a curta duração da vida útil das mercadorias, de modo a sustentar a operação continuada do consumo.

Dessa forma, ambas (a obsolescência programada e as campanhas de marketing), se consolidaram como saída para a gestão da economia pós-guerra em crise, sendo adotadas tanto por governos quanto por indústrias. $\mathrm{O}$ desenvolvimento de um produto, com base na estratégia da obsolescência programada, prevê o fim da sua vida útil, seja pelo desgaste de suas peças, seja pelo avanço tecnológico que torna obrigatória a compra de um modelo mais atualizado. Conforme assinala Silva (2012, p. 187) "a obsolescência programada é filha da sociedade de consumo, mais especificamente do chamado consumismo". Pode-se dizer, assim, que com a articulação entre marketing, produção em massa e obsolescência programada, inaugura-se uma nova configuração social marcada pelo consumismo. Trata-se de uma economia que se nutre da circulação constante e exponencial de novas mercadorias, gerando necessidades diversas tanto de produtos quanto de serviços.

Dando ênfase aos efeitos dessa prática predatória e perigosa em nosso cotidiano, Krenak (2020b, p. 5) complementa: "Hoje estamos todos diante da iminência de a Terra não suportar a nossa demanda”. Também Forti (2019) alerta para a situação limítrofe da produção excessiva de lixo relatando:

Os níveis crescentes de lixo eletrônico, somados ao tratamento e ao descarte inadequados e inseguros, representam desafios significativos para o meio ambiente e a saúde humana. Os equipamentos descartados, tais como geladeiras, telefones, laptops, televisores e lâmpadas, contêm substâncias nocivas, principalmente se os produtos forem tratados de maneira imprópria. Entre os materiais perigosos comumente encontrados no lixo eletrônico destacam-se metais pesados (como mercúrio, chumbo e cádmio) e produtos químicos (como clorofluorcarbonetos CFCs - ou vários retardadores de chama). Ainda assim, a maior parte do lixo eletrônico não é descartada nem tratada adequadamente, acabando em lixões. (FORTI, 2019, p. 8).

Diante desse breve percurso sobre a emergência e consolidação da sociedade de consumo no século XX, cabe questionar quais são as consequências que o mesmo traz para o mundo contemporâneo. Tendo como pressuposto que o principal motor de disseminação das práticas de consumo envolve a subjetividade, a próxima seção visa a analisar como ocorre sua inscrição nas operações de mercado.

\subsection{Uma subjetividade para o consumo}

O modo de vida característico da contemporaneidade, pautado em valores 
capitalistas de produção e consumo, tem causado sérios efeitos colaterais em termos ambientais e sociais. Além das estratégias comerciais que acionam a obsolescência programada, outra dimensão que foi amplamente explorada refere-se à produção e circulação de componentes subjetivos que valorizam as práticas de consumo e de descarte.

Após os anos 1950, novos consumidores, em especial os advindos da guerra, foram lançados em um contexto social repleto de produtos diversificados, evidenciando as possibilidades de satisfação e prazer. Conforme assinala Corrêa (2006, p. 11), "toda a produção foi orientada para atender às necessidades das populações que queriam se compensar por aqueles anos difíceis". Sendo assim, o mundo globalizado e as inovações tecnológicas, sobretudo as digitais, encontraram nas estratégias de marketing uma maneira de atrelar aspectos subjetivos às marcas (BAUMAN, 2008). A preocupação dos profissionais ligados ao marketing, com o passar do tempo, sofisticou-se e passou a considerar as características subjetivas dos consumidores, expondo em campanhas publicitárias não apenas o produto propriamente dito, mas também associando-o às demandas e expectativas que os consumidores poderiam ter. Nesse sentido, experimentamos um universo no qual "a sociedade de consumo desenvolveu-se a um estágio tal que a imagem passou a ocupar o lugar da própria mercadoria" (FONTENELLE, 2005, p. 64). É como se as marcas e as imagens ganhassem vida própria, proporcionando uma conexão direta com os consumidores; o uso da imagem e da marca tornou-se estratégia fundamental para comercialização de novos produtos e serviços.

Bauman (2008) explora outro ângulo ao discutir algumas características do que caracteriza como sociedade de consumidores. Para o autor:

[...] ninguém pode se tornar sujeito sem primeiro virar mercadoria, e ninguém pode manter segura sua subjetividade sem reanimar, ressuscitar e recarregar de maneira perpétua as capacidades esperadas e exigidas de uma mercadoria vendável. A "subjetividade" do "sujeito", e a maior parte daquilo que essa subjetividade possibilita ao sujeito atingir, concentra-se num esforço sem fim para ela própria se tornar, e permanecer, uma mercadoria vendável. A característica mais proeminente da sociedade de consumidores - ainda que cuidadosamente disfarçada e encoberta é a transformação dos consumidores em mercadorias; ou antes, sua dissolução no mar de mercadorias (BAUMAN, 2008, p.20).

O que chama a atenção na análise empreendida por esses dois autores é a dimensão subjetiva transformada em uma oportunidade de mercado. Fontenelle (2005, p. 65) chega a considerar que "o marketing ganha destaque justamente quando a cultura assume o lugar de principal mercadoria do capitalismo contemporâneo". Noções como as de prazer, individualidade, sedução, entre outras dimensões da subjetividade, são pontos de partida para planejar e executar as principais campanhas publicitárias e desenvolver um novo modelo econômico.

Nessa direção, ocorreu uma ampliação do número de pesquisas sobre a esfera subjetiva, buscando vinculá-la ao funcionamento do mercado. Adotando uma perspectiva crítica a esse cenário, Guattari e Rolnik compreendem que estamos imersos na "produção de subjetividade capitalística". (1996, p. 16) Nela, dimensões de ordem subjetiva passam a ser comercializadas, negociadas e compreendidas como oportunidade de mercado e lucratividade. Nas palavras dos autores, "trata-se de sistemas de conexão direta entre as grandes máquinas produtivas, as grandes máquinas de controle social, e as instâncias psíquicas que definem a maneira de perceber o mundo" (GUATTARI; ROLNIK, 1996, p. 27).

Aos poucos, o marketing torna-se a ferramenta central de disseminação dos componentes de subjetivação capitalistas que permeiam a sociedade de consumo. Ele contribui, em alguma medida, para colocar em circulação alguns aspectos subjetivos que alimentam a dinâmica do mercado. Sendo assim, cabe questionar: Quais os efeitos da produção de uma subjetividade voltada para o consumo? É nesse sentido que a questão 
ambiental ganha relevância para este estudo, uma vez que, em nossa perspectiva de análise, o descarte, e sua inevitável produção de lixo, é indissociável de todo esse processo. Assim, entendemos a crise ambiental como uma problemática central decorrente do consumo.

A busca incessante pela compra de novos produtos, a insatisfação pessoal explorada de maneira recorrente, o estímulo às inovações e ao consumo tecnológico têm sido grandes aliados para promover a concentração de capital. Em contrapartida, tal busca tem gerado inúmeros problemas sociais e ambientais, sobretudo no que diz respeito à questão do um acúmulo de lixo em centros urbanos, sem precedentes na história. Apesar de a questão da geração de resíduos na atualidade ter trazido à tona os graves problemas gerados pela sociedade de consumo, ela é sistematicamente negligenciada. O consumidor, imerso nas idealizações exploradas pelas campanhas publicitárias, não se reconhece como um produtor de lixo, fato que tende a glamourizar o ato de consumir. Tudo o que consumimos em escala planetária, transforma-se, rapidamente, em milhões de toneladas de resíduos (VIALLI, 2012; UNEP, 2009). Assim, produzimos mais do que o planeta consegue suportar.

As abordagens críticas da sociedade de consumo englobam não somente o aspecto econômico ou social, mas, especialmente, os seus efeitos ambientais. Entretanto, elas ainda continuam restritas aos contextos acadêmico, militante-ambientalistas e dos movimentos sociais. Trabalhos como de Silva (2012) e Layrargues (2011) indicam o consumismo como um dos responsáveis, senão o principal, por crises ambientais e pela ampliação da exploração dos recursos naturais para a geração de matérias-primas voltadas à fabricação exacerbada mercadorias. Estimativas apontam, conforme considera Silva (2012, p. 186), que "se todos os habitantes do planeta alcançarem as mesmas taxas de consumo dos países desenvolvidos, precisaríamos do equivalente a quatro ou cinco planetas". Desde já é possível dizer que esta situação ganha contornos cada vez mais insustentáveis e de difícil gestão.

Quando o consumo se torna um componente de subjetivação amplamente compartilhado e disseminado socialmente como uma prática natural, seus efeitos são alarmantes. Diante deles, cabe questionar: Quais são os limites desse consumismo e as suas consequências para a sociedade e para a natureza? Como estender a análise do consumo para o debate sobre a sustentabilidade? Podemos falar em sustentabilidade sem questionar as bases atuais do consumo desenfreado? O debate sobre tais questões é delicado e urgente, sobretudo no que se refere às crises ambientais geradas e às possibilidades de adotarmos práticas mais sustentáveis no cotidiano. A seção seguinte abordará essas questões.

\subsection{As crises ambientais e a produção de lixo}

A problemática das relações entre o homem e a natureza é considerada por ambientalistas e cientistas uma das questões mais urgentes a ser enfrentada nos dias de hoje (O'CONNOR, 2002; JACOBI, 2005; KRENAK, 2020a). Os crescentes problemas sociais, políticos e especialmente ambientais, enfrentados pelos diferentes países, têm levado a um debate sobre a preocupante ameaça de catástrofes sociais e ambientais que nos cercam. Tais problemas, entretanto, só podem ser abordados mediante o questionamento incisivo acerca das bases fundamentais do capitalismo vigente, sobretudo no que se refere aos efeitos gerados pelas práticas da sociedade de consumo (LAYRARGUES, 2011; JACOBI; BESEN, 2011; KRENAK, 2020b).

O processo sistemático de destruição da natureza e os recorrentes problemas urbanos vêm sendo gradativamente intensificados pela lógica do consumismo, sendo "a cultura do consumismo um dos alvos da crítica a sociedade moderna" (LAYRARGUES, 2011, p. 189). Isso evidencia a difícil relação entre homem e natureza. As mudanças climáticas no cenário global, o colapso dos oceanos e catástrofes naturais já não são mais apenas previsões alarmistas (STENGERS, 2015; BECK, 2011). São situações concretas, geradas pelo processo 
de mercantilização da natureza, sendo este cada vez mais crescente, incluindo a exploração predatória da biodiversidade global e seus ecossistemas. A exploração desenfreada dos recursos naturais começa, portanto, a demonstrar sua dimensão mais dramática: inundações, secas, poluição do ar, envenenamento dos alimentos com pesticidas (que causam câncer, por exemplo), chuva ácida, deslizamento de terras, contaminação dos lençóis freáticos, acúmulo de lixo nos centros urbanos, o aumento da pobreza e de desigualdades sociais. Esses são problemas crescentes que não podem mais ser negligenciados.

Diante desse cenário, diversos setores da sociedade têm concentrado seus esforços em prol de uma atenção mais focada nas questões ambientais. Nesse sentido, ao final de 1960 e início de 1970, o debate ecológico ganhou destaque nas esferas políticas internacionais, colocando em evidência as noções de sustentabilidade e desenvolvimento sustentável (PIERRI, 2001; FOLADORI, 2001; JACOBI, 2005). Diversos estudos da época alertavam sobre os efeitos destrutivos que o processo acelerado de urbanização e industrialização vinha causando sobre a natureza (EHRLICH, 1968; CARSON, 1969; MEADOWS et. al., 1972; GOLDSMITH et. al., 1972). Além disso, a década de 1970 foi cenário de uma crise econômica mundial (FOLADORI, 2001; O’CONNOR, 2002), sobretudo a do petróleo, que evidenciou a dependência mundial desse recurso natural.

Dentre os debates internacionais, destacamos a realização da Primeira Conferência Mundial sobre o Homem e o Meio Ambiente, realizada em 1972 (Estocolmo - Suécia) e presidida pela Organização das Nações Unidas (ONU). Outra importante conferência a ser demarcada refere-se a proposta efetivada pela Comissão Mundial sobre Meio Ambiente e Desenvolvimento que teve seus trabalhos consolidados em 1987 com a publicação do relatório Nosso Futuro Comum, também conhecido como Relatório Brundtland, (PIERRI, 2001). Estes dois eventos assinalam o momento em que a questão ambiental foi efetivamente introduzida na agenda política mundial. Apesar disso, os avanços em direção a um maior comprometimento com a preservação da natureza ainda são mínimos. Nesse sentido, diversos autores (PIERRI, 2001; O'CONNOR, 2002) têm apontado que as discussões mundiais acerca do desenvolvimento sustentável e dos problemas emergentes nas cidades são temáticas que se concentram, em larga medida, nos aspectos técnicos e econômicos em detrimento de uma dimensão política. Os efeitos destrutivos decorrentes do modo de vida urbano consumista e seus desdobramentos, especialmente no que tange a problemática da geração de resíduos, ainda carecem de análises mais abrangentes.

A produção sistemática de lixo é um dos principais efeitos danosos da sociedade contemporânea consumista. Quanto mais se consome, mais ele é produzido. Temos, portanto, o estabelecimento de "um círculo vicioso que envolve a seguinte sucessão de práticas: produzir bens e serviços - consumir - descartar - produzir lixo" (RODRIGUES; MANSANO, 2013, p. 10). Os países desenvolvidos, embora sejam os maiores produtores de lixo, possuem melhores sistemas de gestão integrada e uma maior capacidade de equacionamento sobre a questão dos resíduos sólidos. Já nos centros urbanos dos países em desenvolvimento, verificam-se grandes dificuldades em assegurar um controle de qualidade ambiental de maneira eficiente, especialmente em se tratando de manutenção de gestão e destinação adequada de resíduos. Só no Brasil, em 2014, a geração total de Resíduos Sólidos Urbanos (RSU) foi de aproximadamente 78,6 milhões de toneladas. Embora, deste total, o índice de cobertura de coleta seja de $90,6 \%$, temos ainda pouco mais de 7 milhões de toneladas de RSU que deixaram de ser coletadas no país neste ano e, consequentemente, tiveram uma destinação inadequada (ABRELPE, 2014). Os resíduos produzidos e não coletados são depositados de maneira imprópria nas avenidas, ruas, córregos, rios e terrenos baldios. Com efeito, isso tem causando a proliferação de insetos e agentes transmissores de doenças, a poluição do ar atmosférico, além de assoreamento de rios, córregos e entupimento de bueiros, com consequente aumento de enchentes nas épocas de chuva (JACOBI; BESEN, 
2011). Tal prática impacta direta ou indiretamente na qualidade da saúde pública e da preservação ambiental. No Brasil, o sistema de coleta seletiva ainda é fragil e a infraestrutura de diversas cidades do país não estão devidamente preparadas para receber os resíduos gerados, em virtude do acelerado ritmo de produção, consumo e descarte (ABRELPE, 2014; JACOBI; BESEN, 2011).

No que se refere à legislação sobre limpeza urbana de nosso país, em particular o manejo dos resíduos sólidos, foi sancionada e aprovada a Política Nacional de Resíduos Sólidos (PNRS), pela Lei n. 12.305, de 2010, regulamentada por meio do Decreto n. 7.404, de 2010, após 20 anos de tramitação no Congresso Nacional. Ela estabelece um importante marco regulatório em nível nacional. A política nacional estabelecida em 2010 definiu alguns objetivos a serem alcançados, dentre os quais destacamos: a eliminação dos lixões de todo o país, a implementação da coleta seletiva e da logística reversa daqueles resíduos considerados perigosos a saúde e ao meio ambiente (que responsabiliza o fabricante pela destinação correta do lixo por ele gerado), visando estabelecer em todo o país, estados e municípios a gestão integrada e o gerenciamento dos resíduos sólidos. Embora a criação de uma política nacional (BRASIL, 2010) possa ter significado um avanço em termos legais e institucionais, percebemos, no entanto, que grande parte dos objetivos propostos pelo plano não conseguiram atingir aos níveis propostos. Pelo contrário, os resultados foram muito abaixo do esperado, conforme apontam os dados apresentados pelo Panorama dos Resíduos Sólidos no Brasil 2014. (ABRELPE, 2014).

Vale ressaltar que o prazo estipulado para cumprimento dos objetivos determinados pela própria política era o final do ano de 2014. Contudo, apesar dos esforços empreendidos desde a implementação da lei e alguns pequenos avanços registrados, as metas principais não haviam sido atingidas; a evolução em termos de gestão de resíduos tem sido bastante lenta, o percentual de resíduos encaminhados para aterros sanitários permaneceu praticamente inalterado nos últimos anos e menos de $65 \%$ dos municípios contavam com iniciativas de coleta seletiva (ABRELPE, 2014). De acordo com o relatório, os índices registrados ao final do prazo estabelecido demonstravam claramente que a situação estava bastante distante daquilo que foi discutido e proposto. Nesse sentido, o gerenciamento compartilhado e integrado dos resíduos sólidos, bem como a destinação e/ou disposição final ambientalmente adequada (BRASIL, 2010) também se tornam ações desafiadoras, à medida que nem governos, nem empresas, nem sequer a sociedade civil conseguem impelementar medidas de gestão, controle e prevenção.

Nota-se que o projeto nacional de não geração, redução e reutilização das mercadorias (BRASIL, 2010) é pouco explorado por campanhas publicitárias governamentais e empresariais. Como já assinalado, tais campanhas tendem a estimular a obsolescência programada e o consumo de massa, negligenciando a produção sistemática de lixo delas decorrentes. Iniciativas capazes de enfrentar os problemas gerados pelo lixo ainda são mínimas e demandam estudos sistemáticos.

\section{TRAJETÓRIA METODOLÓGICA}

A parte empírica desta pesquisa for realizada em uma ONG que atua na coleta e reciclagem de lixo eletrônico em uma cidade de médio porte localizada no interior do estado do Paraná. Trata-se de um estudo de caso qualitativo que se fundamenta na análise específica da produção e destinação de lixo eletrônico. O estudo de caso único implica a escolha de um determinado objeto, seja ele "uma pessoa, um programa, uma instituição, uma empresa ou um determinado grupo de pessoas que compartilham o mesmo ambiente e a mesma experiência" (GODOY, 2010, p. 119). A opção pelo estudo desta ONG como caso único deveu-se ao fato de ser uma iniciativa de reciclagem e destinação de lixo pouco encontrada em nosso país, 
demandando uma análise mais aprofundada e situada.

Ao delimitar a ONG como caso a ser investigado, os pesquisadores deram destaque às percepções de seus gestores no que se refere às práticas de consumo e descarte, buscando conhecer em profundidade o como e o porquê essa iniciativa ganhou consistência, abordando seus aspectos subjetivos, sustentáveis e políticos. O estudo se configura também como estudo de caso descritivo, pois busca apresentar relatos detalhados do contexto histórico e social no qual a organização está inserida.

A unidade de análise foi composta exclusivamente pelos gestores que atuam diretamente no nível administrativo da organização: o gerente e o fundador. O gerente possui, dentre suas atribuições, a responsabilidade por tomar grande parte das decisões gerenciais e financeiras. Trata-se de um profissional com experiência no campo da gestão, com conhecimentos e capacitação técnica nas áreas de administração financeira, gestão empresarial e sistemas de informação. O fundador da ONG é um profissional ligado ao ramo de informática e bastante inserido no debate das questões ambientais da cidade, sendo responsável pela articulação política da organização, com atuação na gestão, prospecção de parcerias e viabilização de campanhas de coletas de lixo eletrônico.

Foram três os instrumentos de coleta de dados adotados: observações, seleção e análise de documentos e entrevistas semiestruturadas. $O$ processo todo de investigação empírica teve a duração de aproximadamente seis meses, com visitas sistemáticas à ONG e análise de documentos por ela disponibilizados. As entrevistas aconteceram com os dois gestores que foram escolhidos por ocuparem uma posição de destaque na história de criação e gestão da ONG, estando envolvidos com questões técnicas, operacionais e políticas, desde a sua fundação. Os dados foram analisados a partir do referencial teórico proposto na primeira parte deste artigo, tendo como norteadores os conceitos de subjetividade, obsolescência programada e consumo.

\section{RESULTADOS E DISCUSSÃO: SOBRE A PRODUÇÃO E O TRATAMENTO DO LIXO ELETRÔNICO}

Apresentamos, agora, a análise das entrevistas realizadas com os gestores da ONG, juntamente com a pesquisa documental. Pode-se notar, no decorrer das observações e entrevistas, que as estratégias de marketing tiveram papel fundamental na consolidação de uma sociedade consumista, conforme reconhecido pelo gerente da ONG quando ele diz:

\footnotetext{
“existe um exagero absurdo com relação ao consumo, principalmente por causa da publicidade. A propaganda é maciça em cima do jovem. O consumo de eletrônico, não só no Brasil, mas no mundo inteiro, tem sido muito grande, em função [...] daquela necessidade que a publicidade incute nas pessoas: de estar sempre no 'topo da linha'. O problema é que a nossa 'sociedade de consumo', a população, está sendo massacrada pela publicidade e pela venda daquela ideia de que você tem que ter sempre, sempre o 'suprassumo', o mais novo. E não é por aí'.
}

O entrevistado evidencia as estratégias de marketing (especialmente a publicidade e a propaganda) como operações fundamentais para a pulverização dos produtos e das marcas. Há uma constatação do caráter sedutor e incisivo que as campanhas midiáticas exercem sobre a população, demonstrando suas estratégias centrais de disseminação do consumismo. Sob o ponto de vista do entrevistado, trata-se de uma cultura que precisa ser combatida. Conforme apontado pelo gerente, as noções implícitas nas campanhas ("suprassumo" e "topo da linha") indicam alguns mecanismos estratégicos das operações de marketing que mobilizam os indivíduos a irem às compras, em busca dos benefícios das inovações e da satisfação das suas necessidades. 
Além disso, o gerente destaca as operações midiáticas como sendo muito bem direcionadas ao universo infantil. Na visão dos entrevistados, nota-se que valores de consumo vêm sendo introjetados nos modos de pensar e agir das crianças e adolescentes, de maneira intensa e precoce, fazendo com que a cultura consumista seja cada vez mais naturalizada e incorporada ao cotidiano. Nessa direção, Bauman destaca:

\begin{abstract}
A sociedade de consumidores concentra seu treinamento, assim como as pressões coercitivas exercidas sobre seus membros desde a infância e ao longo de suas vidas. [...]. Tão logo aprendem a ler, ou talvez bem antes, a "dependência das compras" se estabelece nas crianças. Numa sociedade de consumidores, todo mundo precisa ser, deve ser e tem que ser um consumidor por vocação (ou seja, ver e tratar o consumo como vocação) (BAUMAN, 2008, p. 72-73).
\end{abstract}

O envolvimento de crianças e adolescentes com as mercadorias interfere na construção de suas percepções do mundo do comércio e se configura como aspecto relevante na construção de subjetividades na contemporaneidade. Sobre essa incidência da publicidade na infância, Guattari e Rolnik (1996, p.32) alertam: "Seu tempo é passado principalmente diante da televisão, absorvendo relações de imagem, de palavras, de significação. Tais crianças terão toda sua subjetividade modelizada por esse tipo de aparelho". Os autores ainda destacam: "é desde a infância que se instaura a máquina de produção de subjetividade capitalística, desde a entrada da criança no mundo das línguas dominantes, com todos os modelos tanto imaginários quanto técnicos nos quais ela deve se inserir" (GUATTARI; ROLNIK, 1996, p.40). Nessa direção, o gerente observa:

\footnotetext{
"Existe também, um apelo quanto à posição social do indivíduo na sociedade. [...] Uma televisão $4 K$, por exemplo, não vai fazer a pessoa ficar mais alegre, mais bonita, mais interessante, mais inteligente. Não, não vai! Então, as pessoas têm que ter responsabilidade no momento da compra, do consumo. [...] O Iphone 6 não vai te deixar mais bonito e nem mais inteligente".
}

A televisão 4K ou o Iphone 6, conforme apresentado pelo gerente, ilustram o valor de status e inclusão social que o consumo de marcas e produtos, considerados de ponta, assumem na contemporaneidade. Os produtos tecnológicos e de comunicação são os grandes representantes desses ideais. Trata-se de um ideal socialmente compartilhado e difundido que evidencia, por exemplo, a importância de possuir um celular de última geração ou uma televisão de alta tecnologia. A posse desses equipamentos é compreendida hoje, por parte significativa da população, como algo essencial. O agravante, neste caso, é que os produtos, especialmente os eletroeletrônicos, são consumidos e descartados em um ritmo cada vez mais rápido. Sobre isso, o gerente alerta: "é o caso desses aparelhos de telefone celular de renome".

Em todos os fragmentos destacados até aqui, os entrevistados indicam a presença disseminada de componentes de subjetivação capitalísticos (GUATTARI; ROLNIK, 1996) que, em grande medida, são operacionalizados pelas estratégias de marketing e funcionam como artifícios centrais no capitalismo contemporâneo (FONTENELLE, 2005; RIFKIN, 2001). Conforme salientam, Guattari e Rolnik (1996, p. 27), as dimensões subjetivas foram muito bem absorvidas pela organização capitalista e pelos "sistemas de conexão direta entre as grandes máquinas produtivas, as grandes máquinas de controle social, e as instâncias psíquicas que definem a maneira de perceber o mundo". Pode-se dizer que estamos diante de um processo que se dá em escala global e que é percebido também nas dinâmicas microssociais. Em nível global, isso ocorre à medida que governos e grandes conglomerados empresariais fomentam o ideal de crescimento econômico e progresso social, por meio de novas formas de produção e consumo, sobretudo estimulando políticas de crédito. Já em nível 
microssocial, nota-se que as práticas cotidianas da população estão imersas em processos capitalistas: crianças se divertem cada vez mais por meio de entretenimento pago, ao passo que os adultos buscam aumentar suas rendas com intuito de melhorar seu potencial de consumo.

Além disso, segundo os entrevistados, a facilidade de financiamento das compras também se configura como atrativo e que contribui com a dinâmica do consumismo. Sobre isso, o fundador afirma:

\footnotetext{
"Você leva uma televisão para um conserto custando $60 \%$ do valor de uma nova. Você olha para uma nova, com 3 anos de garantia, parcelado em 36 vezes, no boleto: o cara vai lá e compra! Joga a dele fora! Isso é uma cultura. Mas, a gente tem que trabalhar isso aí para mudar, através de educação ambiental, porque o planeta já não sustenta mais. [...]. Hoje, o planeta precisa que você reaproveite ao máximo aquilo que já se tem".
}

As facilidades de financiamento nas compras, as campanhas publicitárias, os anúncios televisivos, os eventos promocionais, a pulverização de imagens e marcas pelos diferentes meios de comunicação, bem como as diversas estratégias midiáticas, funcionam como "sistemas de conexão direta" (GUATTARI; ROLNIK, 1996, p. 27), entre os consumidores e as "grandes máquinas produtivas" (p. 27). Diz o gerente:

\footnotetext{
"E, dentro do contexto do consumo, este também tem se desenfreado, principalmente pela publicidade, pois as pessoas estão sendo muito influenciadas. As pessoas precisam entender que precisam puxar um pouco o freio de mão, não é? $E$ isso elas não fazem. Elas são envolvidas. Realmente a publicidade é um negócio muito interessante: porque pode fazer o bem ou o mal. Mas o fabricante está certo no ponto dele e nós temos que conscientizar as pessoas do outro lado. [...] A indústria está errada? Dentro do capitalismo, não! Só que eu acho que o cidadão precisa ter consciência. [...] Acho que nós temos que ter responsabilidade, e aî entram a conscientização e responsabilidade".
}

O consumo desenfreado e os interesses dos fabricantes são dimensões assinaladas na fala do gerente. Com isso, mais uma vez, ele evidencia a dimensão subjetiva que o consumo assumiu no cenário contemporâneo e alerta para a necessidade de uma problematização sobre as relações de consumo. Diante disso, alguns trabalhos da ONG são exemplificados por ele como medidas de enfrentamento dessa questão. Sobre isso o gerente diz: "Este tipo de trabalho que nós estamos fazendo. [...] palestras em faculdades, em colégios, em diversas empresas também. Nós vamos e fazemos a palestra, é gratuita, não custa nada. E a gente tenta conscientizar as pessoas que realmente existe uma necessidade de se trabalhar da forma correta". O fundador complementa: "Queremos praticar mais a educação ambiental, daqui pra frente. Queremos, cada vez mais, disseminar palestras nas escolas, nas universidades, nas faculdades, levando o meu negócio e as práticas de consumismo para que se tornem um consumo consciente".

Nota-se a preocupação por parte dos entrevistados em discutir e disseminar valores sustentáveis, de modo que a ONG se torne um canal de comunicação que discuta acerca desses temas. Entre os objetivos da organização, percebe-se, por esses depoimentos, que a ONG se propõe a problematizar o modo produção e consumo de maneira à desnaturalizar, em um nível microssocial e situado, as práticas consumistas da vida contemporânea. Esse tipo de iniciativa, entretanto, ainda é bastante discreto em nossa sociedade, pois os valores disseminados pelas campanhas mercadológicas e midiáticas favorecem a busca pelo consumo das inovações num ritmo cada vez mais veloz, visando à satisfação de expectativas e desejos que nunca cessam. Nas palavras de Bauman (2008, p. 88): “o desejo - entidade muito mais volátil e efêmera. [...] tem a si mesmo como objeto constante, e por essa razão está fadado a 
permanecer insaciável qualquer que seja a altura atingida pela pilha dos outros objetos (físicos e psíquicos)". A volatilidade e a insaciabilidade das expectativas dos consumidores impulsionam a prática consumista. O consumo, então, se intensifica e, numa proporção equivalente à produção de lixo. Nessa direção, analisando o espaço físico da ONG e seus objetos, o fundador comenta:

"Tudo que você está vendo aqui: computador, impressora, televisão, são todos aparelhos que vieram do lixo reciclável. É muito lixo. Se não existisse a ONG [...], onde estariam todos esses materiais aí? Provavelmente, estariam lá no aterro. É um lixo gravíssimo. Plásticos, muitos produtos que nem mesmo se deterioram. [...]. O volume de coleta de lixo eletrônico é grande: em torno de 60 toneladas por mês, pois coletamos em diversos municípios. [...]. Eu acho que eu não coleto nem 0,01\%, do que é gerado por aqui na região, de lixo eletrônico".

Abordando essa mesma temática, o gerente afirma:

“[...] nossa cidade, eu diria, é uma das 'campeãs' de produção de lixo eletrônico do Paraná inteiro. [...] Para você ter uma ideia, nos aterros sanitários: $70 \%$ do que contém lá é metal pesado. Por causa do descarte inadequado feito antes da gente. [...]. Temos que conscientizar; conscientizar 'governos', nós temos que 'lutar' para educar os mais jovens. Educar os mais jovens no quesito: consumo”.

Como já evidenciado, os entrevistados acreditam que a população, especialmente os jovens, está conectada a processos midiáticos massivos, trocando e substituindo seus aparelhos eletrônicos por novos modelos, de maneira muito natural e acelerada. Eles evidenciam em seus depoimentos que as estratégias de marketing, entre outros discursos delineados pelos sistemas de conexão e operação do capitalismo, contribuem para que o consumidor busque novos produtos e serviços, satisfaça momentaneamente suas necessidades e expectativas, mas não se visualize como um produtor de lixo. Trata-se de uma espécie de glamourização do consumo. Isso ocorre, sobretudo, com os produtos eletroeletrônicos que são substituídos e descartados de maneira corriqueira, conforme evidencia o fundador: "Às vezes, o cara descarta uma televisão de LCD - e que hoje é realidade. Hoje é realidade o pessoal descartar TV de LCD. Você vai consertar e não compensa". Também o gerente complementa essa ideia dizendo:

\footnotetext{
"[...] foi lançada, recentemente, a televisão 4K, é muito bonita e tudo mais. Mas, existe transmissão 4K? Não. Existe DVD 4K? Não! [...]. Não existe suporte para este tipo de tecnologia. Então as pessoas compram por quê? Porque é novidade, porque é coisa boa e joga fora aquela TV de LED dele. [...] Nós acostumamos a sempre falar sobre isso, inclusive, dentro das empresas: 'Calma. Não vai trocar os equipamentos agora, continue com eles. Use o equipamento até o final da vida útil dele, se adapte, vale a pena'. Não há necessidade de você ficar trocando de celular de seis em seis meses, só porque o outro é mais bonito e tem mais capacidade”.
}

Para os entrevistados, a prática da ONG constata diariamente que os ciclos de vida dos produtos diminuem a cada nova versão. Além da curta durabilidade física do produto, outro problema ganha relevância: à medida que novos modelos são lançados (em escala industrial), o equipamento anterior torna-se, simbolicamente, obsoleto (BAUMAN, 2008; LAYRARGUES, 2011), mesmo que ainda se mantenha em perfeito estado funcional. De acordo com o fundador: "Muita coisa vem pra cá, em função de ter saído de linha, mas ainda tem utilidade pra pessoa. [...] às vezes, 'o cara' troca uma câmera, porque a câmera tem uma resolução menor ou uma maior; ou a câmera tem flash na frente; ou o celular tem flash na frente e o outro não tinha”. Nessa mesma direção, comenta o gerente: 


\begin{abstract}
"Tudo isso é programado, a gente vê muito disso, ou via muito disso (hoje praticamente não tem mais nada) nas câmeras digitais. Primeiro, lançava a de 2Mega, depois a de 4Mega, depois a de 5Mega. Quer dizer: já estava tudo programado dentro das empresas, das indústrias, para que a cada seis meses laçarem o produto um pouquinho melhor, para que as pessoas jogassem aqueles anteriores fora e comprassem novos. [...]. As indústrias produzem produtos para durarem um determinado período de tempo: muito pouco. Aqui no Brasil, nós estamos em torno de um ano e dois meses, a um ano e meio; porque o equipamento mandado pro Brasil, por exemplo, dos fabricantes estrangeiros, ao invés de ter uma peça de metal que iria durar mais, eles colocam plástico. E existe uma série de modificações que eles fazem, e para quê? Para que o produto, em um ano, um ano e pouco, 'morra' e você compre outro'.
\end{abstract}

É notável pelos depoimentos que além da obsolescência da mercadoria está consolidada uma situação objetiva: o produto, de fato, deixa de funcionar, seja integral, seja parcialmente. Conforme assinalado pelo gerente, os fabricantes utilizam peças com durabilidade de curto prazo para elaboração de seus produtos, fazendo com que os demais componentes se danifiquem rapidamente e não possam ser substituídos, seja por falta de peça de reposição, seja pela inviabilidade financeira de seu conserto. Além disso, as campanhas de marketing, com o lançamento de produtos em novas versões, provocam um desvio da função primária dos produtos, seu valor de uso. Com isso, ainda que o produto esteja em perfeito funcionamento e dentro do prazo de vida útil, diante do lançamento de novos modelos, eles são considerados simbolicamente ultrapassados. Para Layrargues (2011, p. 190), "a obsolescência planejada e a descartabilidade são hoje elementos vitais para o modo de produção capitalista, por isso encontram-se presentes tanto no plano material como no simbólico".

Valores subjetivos também reforçam a dinâmica do descartável. São componentes subjetivos, colocados em circulação, de maneira intensa, e circunscritos nos processos "capitalísticos" (GUATTARI; ROLNIK, 1996) de consumo e descarte. O que isso significa? Modos de vida delineados e disseminados pela lógica institucional capitalista. Dentre eles estão ideias como de inovação e expansão produtiva, expectativa pelo novo, relações comerciais de curto prazo e a glamourização do consumo que trazem consigo a noção de obsolescência. Sobre isso relata o gerente:

\footnotetext{
"A população não conhece o perigo, não conhece o perigo. [...] Então, há necessidade de conscientização da população. É o que eu falei: um equipamento de última geração, um computador de última geração ou um celular de última geração não vai deixar você mais bonito, não vai deixar você mais inteligente, não vai deixar você mais atraente. [...]. Nós pedimos e tentamos conscientizar a população, nós 'brigamos' para que isso realmente funcione. Para realmente evitar um problema maior para população que virá depois de nós. Nossa responsabilidade também é essa. Nós temos que 'brigar' por isso; [...]. Parar com esse excesso de consumo, analisar o que vai comprar. Não é só o produto eletrônico. Ele tem que ter responsabilidade em tudo. Na hora de comprar comida, na hora de comprar equipamento eletrônico, na hora de comprar sapato, na hora de comprar combustível. Tudo isso ele precisa se conscientizar e parar de jogar dinheiro fora e ter um retorno correto naquilo que ele precisa".
}

Em complemento a essa ideia, relata o fundador:

\footnotetext{
“Aqui, eu ainda estou apenas na área do eletrônico. Mas, tem outras áreas que você vê e que não tem, assim... Embalagens de alimentos, até mesmo carros - outro dia eu estava vendo algo sobre carros -, você vê que não tem mais espaço pros carros na cidade. Você vê essas garagens, todas entupidas de carros, entendeu! Pessoas querendo trocar por carros novos, concessionárias abarrotadas dizendo: 'Olha, saiu um modelo novo'. E, o que nós estamos fazendo com os carros que estão
} 
ficando? Então, tem outras áreas aí também que não estão com os problemas resolvidos [...]. Fiz uma experiência, há pouco tempo atrás com sofá. Porque eu também vejo que o sofá impacta bastante em uma cidade. Você não vê reciclagem de sofá. Você não vê reciclagem de colchão. Isso também é uma coisa que, um grande centro como Londrina/PR, precisava ser pensado, não é? Precisava ter alguém para promover isso. A gente não deveria fechar os olhos para uma coisa que você sabe que não tem: 'ah, mas não tem reciclagem de colchão, não tem reciclagem de sofá'. Onde eu jogo meu sofá quando eu compro outro? O sofá impacta muito visualmente, como um sofá jogado na rua. E aí você fala: 'poxa, mas os fundos de vale estão todos contaminados'; mas, não tem uma política para se jogar um sofá fora! Não tem uma política para se jogar um colchão fora! Um travesseiro. Vai acabar enterrado! E isso tem reflexo na vida do planeta".

Os argumentos apresentados pelos entrevistados problematizam algumas questões importantes sobre a obsolescência e o descarte de mercadorias. Eles entendem que a população precisa de melhores direcionamentos sobre como tratar os resíduos gerados e que faltam iniciativas nas prefeituras para coleta e destinação adequada de produtos que foram descartados. Nesse sentido, para Layrargues:

[...] o que deveria ser discutido é a diferença entre o desejo de ter uma geladeira para conservar alimentos e o desejo de trocá-la a cada novidade, o que acrescenta uma nova função concreta ou simbólica ao aparelho tecnológico. Esse é o problema do consumismo, uma questão eminentemente cultural, relacionada à incessante insatisfação com a função primeira dos objetos em si (LAYRARGUES, 2011, p. 190)

A insatisfação traduzida na pratica consumista, demonstra a falta de conscientização e/ou conhecimento da população sobre os riscos e impactos ambientais que o excesso de consumo e a produção de resíduos causam ao meio ambiente. $\mathrm{O}$ fundador, cita o exemplo dos carros e do sofá demonstrando muito bem a inabilidade e falta de iniciativas, por parte das organizações, sejam elas privadas ou públicas, em proporcionar programas para a destinação correta dos produtos que são descartados. As pessoas parecem não se visualizarem como produtoras de lixo, situação agravada pela obsolescência das mercadorias e pelo lançamento de novos produtos que induzem os consumidores à substituição de seus pertences. Porém, a produção de lixo decorrente desse processo passa despercebida pela própria população, uma vez que não há iniciativas de divulgações, de maneira massiva, sobre como e onde descartar.

Nessa conjuntura, emerge o problema da mudança do padrão de produção e consumo advogada pelo ambientalismo alternativo, que visualiza a necessidade tanto da mudança qualitativa da produção, alterando insumos e matrizes energéticas, como a diminuição da descartabilidade e a eliminação da obsolescência planejada, material e simbólica (LAYRARGUES, 2011, p. 191).

Embora o consumo e as inovações sejam questões exploradas pelas campanhas de marketing e pelos sistemas de expansão de crédito, a obsolescência e o descarte tornam-se dimensões esquecidas pelos consumidores, fabricantes e governos. Sobre a obsolescência e o descarte, o gerente complementa:

"As empresas hoje, fazem produtos para durarem menos tempo: a chamada obsolescência programada. Uma televisão de LED, por exemplo, tem uma vida útil de um ano e meio. Depois disso ela 'queima', você vai comprar a peça interna dela e já não existe mais. Porque já mudaram todos os modelos, mudaram tudo, e para quê? Para que você continue consumindo. [...]".

Nessa perspectiva, o fundador afirma ainda: “nossa televisão não aguenta três anos! 
Compra uma televisão e observe, não dura três anos!". Ao lançar no mercado novas mercadorias e tecnologias, a indústria e o marketing articulam suas campanhas com ênfase nos benefícios vindouros a partir da aquisição (CORRÊA, 2004; RIFKIN, 2001). Os produtos adquiridos, ainda em pleno funcionamento (como ocorre com aparelhos celulares, televisores, tablets, etc.), tendem a ser descartados, trocados, substituídos. Na perspectiva do gerente:

\begin{abstract}
“Por exemplo: o 'Pokemon Go'. Só funciona nos equipamentos que são certificados por eles (criadores do aplicativo). Quem tem um smarphone comum, por exemplo, não vai conseguir baixar o aplicativo. Eles, portanto, forçam, inclusive através do próprio programa e do aplicativo, o uso 'daqueles' equipamentos compatíveis [...], e muitas vezes são bem mais caros".
\end{abstract}

O exemplo sugerido pelo gerente, ilustrado pelo jogo Pokemon Go (aplicativo de celular para caça de monstros de desenho animado em ambientes virtuais e reais monitorados por GPS e que teve grande repercussão entre os anos de 2016 e 2019), demonstra um caso de obsolescência da mercadoria. À medida que os aparelhos celulares antigos não possibilitam o download do referido aplicativo, muitos adolescentes, e mesmo adultos, se sentem na obrigação ou têm vontade (BAUMAN, 2008) de adquirir um modelo de aparelho celular mais novo, compatível com o aplicativo recém-lançado pela empresa que detém os direitos comerciais do jogo.

O que isso significa? Dentre outras coisas, que o lançamento de novos produtos, com diferentes funcionalidades e configurações, tem acelerado o processo de obsolescência das mercadorias. A troca do produto, neste caso, torna-se praticamente inevitável. Isso corresponde a uma espécie de estratégia híbrida entre as campanhas de marketing e a obsolescência programada. À medida que as empresas lançam no mercado novos produtos com diferentes configurações tecnológicas, os equipamentos antigos tornam-se automaticamente obsoletos e destinados à lata de lixo, mesmo estando, ainda, em perfeito funcionamento. Bauman assinala:

\begin{abstract}
Afinal de contas, nos mercados de consumidores-mercadorias, a necessidade de substituir objetos de consumo "defasados", menos que plenamente satisfatórios e/ou não mais desejados está inscrita no design dos produtos e nas campanhas publicitárias calculadas para o crescimento constante das vendas. A curta expectativa de vida de um produto na prática e na utilidade proclamada está incluída na estratégia de marketing e no cálculo de lucros: tende a ser preconcebida, prescrita e instilada nas práticas de consumidores mediante a apoteose das novas ofertas (de hoje) e a difamação das antigas (de ontem) (BAUMAN, 2008, p.31).
\end{abstract}

A maioria dos bens materiais perde sua importância e utilidade, por vezes, antes mesmo de terem sido integralmente desfrutados. Novas necessidades exigem novas marcas e mercadorias, trata-se de um fluxo contínuo e cada vez mais veloz. Neste caso, o gerente ainda relata outra situação, referindo-se às mudanças tecnológicas do sinal analógico dos televisores para o sinal digital:

\footnotetext{
"Principalmente as televisões de tubo, aquelas mais antigas. Daqui alguns dias, vai se intensificar o sinal 'digital' substituindo o 'analógico' e, com isso, a quantidade de televisores de tubo que estamos recebendo é um absurdo. Tivemos que alugar outro barracão, somente para desmontar as televisões de tubo. Então, está havendo uma demanda muito grande desse tipo de produto, os televisores de tubo sendo descartadas. Elas envenenam absurdamente, contêm chumbo e fósforo, trata-se de um perigo absurdo e as pessoas jogam em fundo de vale".
}

Vale salientar que parte da dinâmica de funcionamento da sociedade de consumo gera um ciclo que se retroalimenta: produção de subjetividade pelos dispositivos capitalistas, 
consumo, descarte, produção de lixo. Nesse sentido, localizamos as quadro dimensões que ajudam a dar consistência a esta categoria de análise: o consumo, a dinâmica de inovação das tecnologias e dos produtos, as campanhas de marketing e as operações de obsolescência. A articulação desses elementos é a condição para o funcionamento do capitalismo contemporâneo. Seus efeitos são sentidos de modo significativo na natureza. Analisando o descarte especificamente gerado pela construção civil, Quaglio e Arana (2020, p. 467) alertam que as práticas inadequadas de destinação e tratamento do lixo "causam danos ambientais como degradação e poluição do solo e corpos d'água e mananciais, bloqueio do sistema de drenagem urbano, crescimento de enchentes, proliferação de doenças, degradação da paisagem urbana".

Os dados analisados mostram que a durabilidade e o uso prolongado são características cada vez menos compatíveis com a dinâmica de funcionamento da sociedade de consumo. Há uma relação direta entre valores efêmeros e a busca incessante pela inovação. $\mathrm{O}$ culto às imagens, a espetacularização das campanhas publicitárias, a rápida expansão tecnológica e dos meios de comunicação em massa, bem como o apelo aos benefícios da inovação, têm colocado o marketing como área de intervenção fundamental para o funcionamento da sociedade de consumo contemporânea (FONTENELLE, 2005; BAUMAN, 2008). Suas articulações midiáticas, juntamente com as inovações tecnológicas e as operações de obsolescência das mercadorias têm produzido modos de vida consumistas e descartáveis.

Um dos resultados deste processo são pilhas de lixo acumuladas nos ambientes urbanos. Questões como o acúmulo de lixo e os impactos ambientais decorrentes desse desenvolvimento, porém, precisam ser problematizadas e desnaturalizadas, pois os riscos de danos ambientais estão cada vez mais evidentes no cenário contemporâneo. Defendendo a ideia de um ecossocialismo, Löwy (2019) esclarece que enfrentar de maneira consistente a nossa relação predatória com o meio ambiente requer disposição para transformações radicais. Em suas palavras, nesse difícil processo haveremos de

\begin{abstract}
confrontar tensões entre as necessidades de proteger o meio ambiente e atender necessidades sociais, entre imperativos ecológicos e o desenvolvimento da infraestrutura, entre hábitos de consumo popular e a escassez de recursos, entre impulsos comunitários e cosmopolitas. Lutas entre desejos em competição são inevitáveis. Portanto, pesar e medir tais interesses deve tornar-se tarefa de um processo democrático de planejamento, liberto dos imperativos do capital e da geração de lucros, para se encontrarem soluções através de discursos transparentes, plurais e abertos ao público (LÖWY, 2019, p. 9).
\end{abstract}

O consumo e a produção de bens e serviços têm se expandido como jamais visto na história humana. Os avanços científicos e tecnológicos têm proporcionado grandes melhorias na vida cotidiana da população de modo geral. Ao final da apresentação dos resultados desta pesquisa acumulamos informações para questionar: Quais os impactos desse modo de vida consumista e descartável sobre a natureza?

\title{
5 CONSIDERAÇÕES FINAIS
}

A análise empreendida no decorrer deste trabalho buscou dar destaque às práticas de consumo, à gestão e destinação do lixo bem como aos seus efeitos ambientais. Ao final deste percurso, destacamos quatro pontos que sintetizam as conclusões às quais se chegou com este trabalho. Primeiramente, ressaltamos que todo consumidor é, simultaneamente, um produtor de lixo. Tal situação, como visto, é pouco ou nada abordada em campanhas publicitárias. Assim, o que se nota é a recorrente intensificação da obsolescência das mercadorias empreendida por uma parte significativa das indústrias que desconsideram sua responsabilidade nessa produção, com objetivo claro de aumentar sua rentabilidade. Nessa 
direção, caminham também as estratégias de marketing que reforçam a adesão a valores de mercado, praticamente desconsiderando as possibilidades de construir um modo de vida mais sustentável.

Em segundo lugar, consideramos que a negligência nas campanhas publicitárias em relação à geração de lixo deve-se ao fato de que este (o lixo) praticamente atrapalha as estratégias de venda que buscam estimular novas formas de consumo e novos modos de satisfação de necessidades. Neste caso, o princípio da reciclagem acaba por amenizar os efeitos do consumo e do descarte. Assim, o consumidor sente que pode consumir tranquilamente, uma vez que a reciclagem amenizaria ou mesmo anularia o problema ambiental. Será mesmo? Apesar de reconhecer a importância da reciclagem nesse momento histórico, questionamos se ela, em alguma medida, não estaria servindo para legitimar ainda mais a prática consumista da sociedade contemporânea, uma vez que não coloca diretamente em xeque os efeitos corrosivos do ato de consumir. A tendência quase exclusiva em valorizar - o que não quer dizer realizar de fato - as práticas de reciclagem por parte de empresas privadas e governos, em detrimento dos princípios da não-geração, da redução e da reutilização, reduz o problema a uma esfera que não questiona os modos de produção e a gestão do lixo.

Como terceiro ponto, cabe salientar que o problema investigado neste trabalho trouxe à tona dimensões relativamente pouco problematizadas na área de Administração que se referem às consequências destrutivas do modo de produção e consumo contemporâneos. Tal constatação diz respeito, sobretudo, à geração de resíduos sólidos nos centros urbanos, em particular a geração excessiva de resíduos eletroeletrônicos. Reconhecemos, assim, a necessidade urgente de que gestores e/ou estudantes da área, tenham acesso a uma formação capaz de elaborar a crítica necessária ao modos de produção capitalista e a seus desdobramentos em consumo e produção de lixo.

Em quarto lugar, destacamos que iniciativas como a que encontramos na ONG analisada ainda são raras em nosso país, fato que coloca dois problemas a serem considerados em novos estudos: $1^{\circ}$ ) A necessidade de identificar organizações que já atuam na preservação ambiental, mas que ainda são discretas quando comparadas com o cenário nacional da produção; $2^{\circ}$ ) A possibilidade de ampliar e aprofundar estudos que deem visibilidade a tais iniciativas, ainda que estas comportem uma esfera microssocial.

Diante desses quatro pontos, cabe, ainda, perguntar: Como repensar os modos de vida, as formas de gestão organizacionais e as possibilidades de práticas mais sustentáveis diante da dualidade consumo-descarte? Podemos falar em sustentabilidade sem problematizar a sociedade de consumo, sua tendência à exploração predatória da natureza e sua inevitável produção de lixo? São questões urgentes que colocam a demanda por discussões entre diferentes agentes socias a fim de que a relação entre consumo e produção de lixo seja desnaturalizada e colocada em debate. 


\section{REFERÊNCIAS}

ABRELPE - Associação Brasileira de Empresas de Limpeza Pública e Resíduos Especiais. Panorama de Resíduos Sólidos no Brasil 2014. São Paulo: Abrelpe, 2014.

BARBOSA, L. Sociedade de consumo. Rio de Janeiro: Jorge Zahar, 2004.

BAUDRILLARD, J. A sociedade de consumo. Lisboa: Edições 70, 1995.

BAUMAN, Z. Modernidade líquida. Rio de Janeiro: Jorge Zahar, 2001.

BAUMAN, Z. Vida para consumo: a transformação das pessoas em mercadoria. Rio de Janeiro: Jorge Zahar, 2008.

BECK, U. Sociedade de risco: rumo a uma outra modernidade. 2. Ed. São Paulo: Editora 34, 2011.

BRASIL. Lei n. 12.305, de 2 de agosto de 2010. Institui a política nacional de resíduos sólidos; altera a lei $n^{\circ}$ 9.605, de 12 de fevereiro de 1998; e dá outras providências. Centro de Documentação e Informação, Brasília: Edições Câmara, 2010.

CARSON, R. Primavera silenciosa. São Paulo: Melhoramentos, 1969.

COBRA, M. Um resumo do percurso do Marketing Brasileiro. Revista FAE Business, n. 4, dez. 2002.

CORRÊA, R. Comunicação integrada de marketing: uma visão global. São Paulo: Saraiva, 2006.

EHRLICH, P. R. The population bomb. New York: Oxford University Press, 1968.

FOLADORI, G. Limites do desenvolvimento sustentável. Campinas: UNICAMP, São Paulo: Imprensa Oficial, 2001.

FONTENELLE, I. A. O trabalho da ilusão: produção, consumo e Subjetividade na sociedade contemporânea. Interações, Campo Grande, v. X, n. 19, p. 63-86, jan./jun., 2005.

FORTI, V. O crescimento do lixo eletrônico e suas implicações globais. Panorama Setorial da Internet, v. 4, n. 11, p. 1-19, 2019.

GODOY, A. S. Estudo de caso qualitativo. In: GODOI, C. K.; BANDEIRA-DEMELO, R.; SILVA, A. B. (orgs). Pesquisa qualitativa em estudos organizacionais: paradigmas, estratégias e métodos. 2. ed. São Paulo, p. 115-145, 2010.

GOLDSMITH, E. et al. A blueprint for survival. Penguin: London, 1972.

GUATTARI, F; ROLNIK, S. Micropolítica: cartografias do desejo. 4. ed. Petrópolis: Vozes, 1996.

JACOBI, P. R. Educação ambiental: o desafio da construção de um pensamento crítico, 
complexo e reflexivo. Revista Educação e Pesquisa FE-USP, São Paulo, v. 31, n. 2, p. 302313, maio/ago. 2005.

JACOBI, P. R.; BESEN, G. R. Gestão de resíduos sólidos em São Paulo: desafios da sustentabilidade. Estudos Avançados, 25, v. 71, p. 135-158, 2011.

KRENAK, A. Ideias para adiar o fim do mundo. São Paulo: Companhia das Letras, 2020a.

KRENAK, A. O amanhã não está à venda. São Paulo: Companhia das Letras, 2020b.

LAYRARGUES, P. P. O cinismo da reciclagem: o significado ideológico da reciclagem da lata de alumínio e suas implicações para a educação ambiental. In: LOUREIRO, C. F. B.; LAYRARGUES, P. P.; CASTRO, R. S. (Orgs.). Educação ambiental: repensando o espaço da cidadania. 5. ed. São Paulo: Cortez, 2011.

LIMA, D. N. O. Consumo: Uma perspectiva antropológica. Petropolis: Vozes, 2010.

LÖWY, M. O que é o Ecossocialismo. Esquerda. Fev., 2019.

MEADOWS, D. H. et al. The limits to growth: a report for the Club of Rome's project on the predicament of mankind. New York: University Books, 1972.

O’CONNOR, J. ¿Es posible el capitalismo sostennible? In: ALIMONDA, H. Ecologia politica. Naturaleza, sociedad y utopia. Buenos Aires: CLACSO, p. 27-52, 2002.

PIERRI, N. El Proceso histórico y teórico que conduce a la propuesta del desarrollo suntentable. In: PIERRI, N.; FOLADORI, G. (Eds.) Sustentabilidade? Desacuerdos sobre el desarrollo sustentable. Montevideo: Trabajo y Capital, 2001.

QUAGLIO, R. S.; ARANA, A. R. A. Diagnóstico da gestão de resíduos da contrução civil a partir da leitura da paisagem urbana. Sociedade \& Natureza, v. 32, p. 457-471, 2020.

RIFKIN, J. A Era do acesso. São Paulo: Makron Books, 2001.

RODRIGUES, R. R. J.; MANSANO, S. R. V. Consumir e Descartar: verbos perigosos? In: CAMARGO, H. W. C.; MANSANO, S. R. V. (Orgs). Consumo e modos de vida. Londrina: Syntagma Editores, 2013.

SANTOS, T. et al. O desenvolvimento do marketing: uma perspectiva histórica. Revista de Gestão USP, São Paulo, v. 16, n. 1, p. 89-102, jan./mar., 2009.

SASSEN, S. Expulsões: brutalidade e complexidade na economia global. Rio de Janeiro: Paz e Terra, 2016.

SILVA, M. B. O. Obsolescência programada e teoria do decrescimento versus direito ao desenvolvimento e ao consumo (sustentáveis). Veredas do Direito, Belo Horizonte, v. 9, p. 181-196, 2012.

STENGERS, I. No tempo das catástrofes - resistir à barbárie que se aproxima. São Paulo: Cosac Naify, 2015. 
UNEP - UNITED NATIONS ENVIRONMENT PROGRAMME. Recycling - from E-waste to resources: Sustainable Innovation and Technology Transfer Industrial Sector Studies. UNEP DTIE. 2009.

VIALLI, A. Seu computador velho vale dinheiro. Guia Exame de Sustentabilidade. São Paulo. Abril, Nov. 2012. 